\title{
Research on Safety of Fine Tailings Dam under the Influence of Saturation Line Distribution Characteristics
}

\author{
Shiguo Sun ${ }^{1}$, Pei Guo ${ }^{2}$ a , Yinghai Zhang ${ }^{3}$ and Zhenhua Su ${ }^{4}$ \\ 1College of Architecture, North China University of Technology, Beijing, 100144 China
}

\section{a343065792@qq.com}

\begin{abstract}
Key words:Fine-grained tailings dam, Saturation line, Seepage, Stability analysis
Abstract. The safety operration of tailing spond always plays a significant role in the whole mining production. With the tailings particle size is becoming smaller and smaller and the fill dam is higher and higher, the stability of tailings dam is becoming worse and worse, so the stability of fine-grained tailings dams has become the key and hot spot in the tailing dam engineering. In this paper, taking a tailing as the research object, by theoretical study and numerical simulation, the saturation line and stability of the tailing dam body with different heights and different operation conditions were calculated and analyzed, and the ralationship between saturation line morphological characteristics and dam body stability were studied. Three-dimensional numerical model was established by MIDAS program, to analyze the stability of fine-grained tailings dam in current height and design height, to get the law of dam body stress and strain.
\end{abstract}

\section{Introduction}

The safety operration of tailing spond always plays a significant role in the whole mining production. With the tailings particle size is becoming smaller and smaller and the fill dam is higher and higher, the stability of tailings dam is becoming worse and worse, so the stability of fine-grained tailings dams has become the key and hot spot in the tailing dam engineering ${ }^{[1]}$. According to incomplete statistics, about $25 \%$ of tailings dam accident were caused by the failure control of seepage and the high position of saturation line, so the saturation line is also called the lifeline of the tailings dam. The tailings dam accident can not only bring great losses to people,s life property, but also destroy the environment seriously, therefore, studying the morphological characteristics of saturation line and its role in tailing dam safety has high academic value and significant economic and social benefits ${ }^{[2]}$.

In this paper, taking a tailing as the research object, the tailings of physical and mechanical properties are tested to obtain its mechanical parameters. By theoretical study and numerical simulation ${ }^{[3]}$, the saturation line and stability of the tailing dam body with different heights and different operation conditions were calculated and analyzed, and the relationship between saturation line morphological characteristics and dam body stability were studied.

\section{Fine Gained Tailings Physical Properties}

Tailings dam accumulation of abandoned tailings sites concentrator emissions, therefore, at a location different from the accumulation of tailings dam depends largely on the nature of the concentrator tailings original size ${ }^{[4]}$. Beach deposited by the discharge port respectively, from the discharge port $30 \mathrm{~m}, 60 \mathrm{~m}$, $90 \mathrm{~m}$ at taking four points; sand settling in the sand pile top, middle and lower to take the three points, respectively. After sieving test, the results are classified as fine sand and silt, according to the definition of fine tailings, determination mine belongs fine tailings.

Table 1 Original tailings size distribution

\begin{tabular}{|ccccc|}
\hline Particle size/mm & $<0.01 \mathrm{~mm}$ & $<0.019 \mathrm{~mm}$ & $>0.074 \mathrm{~mm}$ & $>0.037 \mathrm{~mm}$ \\
\hline $\begin{array}{c}\text { The proportion of } \\
\text { content particles }(\%)\end{array}$ & $40 \%$ & $50 \%$ & $20 \%$ & $30 \%$ \\
\hline
\end{tabular}


Table 2 Physical and mechanical parameters of tailings material layer

\begin{tabular}{|c|c|c|c|c|c|}
\hline $\begin{array}{l}\text { Name of the } \\
\text { material }\end{array}$ & $\begin{array}{l}\text { Natural unit weight } \\
\qquad / \mathrm{kN} \cdot \mathrm{m}-3\end{array}$ & $\begin{array}{c}\text { Saturated unit } \\
\text { weight } \\
\text { /kN.m-3 }\end{array}$ & $\begin{array}{l}\text { Internal friction angle } \\
\qquad /{ }^{\circ}\end{array}$ & $\begin{array}{l}\text { Cohesion } \\
\qquad / \mathrm{kPa}\end{array}$ & $\begin{array}{c}\text { Permeability } \\
\text { coefficient } \\
\text { /cm } \cdot \mathrm{s}-1\end{array}$ \\
\hline Initial dam & 21.5 & 23.0 & 42 & 10 & $1.2 \mathrm{e}-2$ \\
\hline Sinking sand dam & 19.2 & 20.6 & 32 & 8.8 & $2.9 \mathrm{e}-4$ \\
\hline Fine sand & 19.5 & 22.4 & 28 & 7.9 & $5.6 \mathrm{e}-4$ \\
\hline Tail powder & 19.9 & 21.4 & 26 & 9.8 & $2.2 \mathrm{e}-4$ \\
\hline Tail sub clay & 20.8 & 21.6 & 24 & 10.6 & $3.5 e-5$ \\
\hline Dam foundation & 1.80 & 19.0 & 24 & 30 & $1.0 \mathrm{e}-6$ \\
\hline
\end{tabular}

\section{Stability Analysis of the Limit Equilibrium Method for Fine Tailings Dam}

SEEP/W in the application of GEO - Studio program module for seepage field simulation, and the stability of the tailings dam is calculated. In normal water level conditions, for example by two kinds of calculation methods to solve dam in the elevation of the status quo and heightening the minimum safety factor and the most dangerous slip surface ${ }^{[5]}$, and the computational results were compared and analyzed. In the dam material, the material parameters are combined with the model of the moire Coulomb model. The specific values of the material parameters are combined with the laboratory experiments and the comprehensive engineering experience ${ }^{[6]}$. The material parameters are shown in Table 2.

The main section of the dam is calculated by using the software to establish the $3 \mathrm{D}$ model of the tailings dam ${ }^{[7]}$, and the seepage stability of the dam under normal condition is analyzed by using MIDAS software. The water head of the tailings dam can be considered to be constant in a short period of time. Thus, the inner flow of the dam can be regarded as the steady flow.

(1) Status quo of the dam elevation

Calculation and analysis of the model. Get normal water level dam body under the condition of minimum safety factor of 1.51. Figure 3.1.1 is taken from $750 \mathrm{~m}$ elevation of the main section of the dam body three-dimensional drawing.

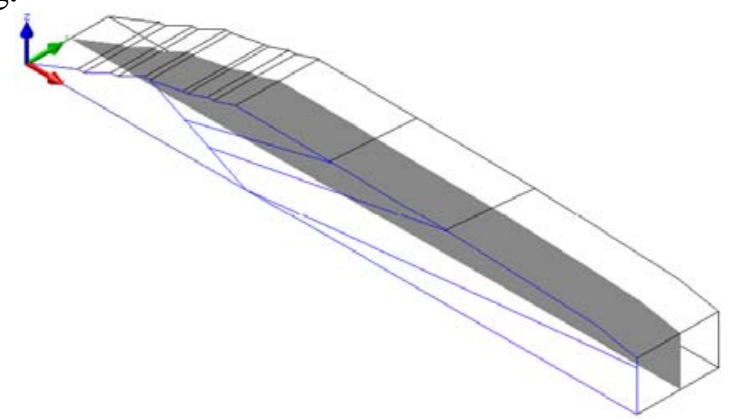

Figure 3.1.1 Tailings dam elevation $750 \mathrm{~m}$ of main section $3 \mathrm{~d}$ drawing

Figure 3.1.2 dam is the elevation of $750 \mathrm{~m}$ in the normal water level running stable after horizontal displacement contour map. Maximize the figure shows that horizontal displacement are in the middle of the downstream of the dam slope initial position, and the maximum value of about $0.441 \mathrm{~m}$ and $0.520 \mathrm{~m}$ respectively, the displacement is not big, and the safety of the dam is not much affected. In addition, the equivalent displacement curve of dam left half arc shape distribution, and the location of the dam slope is close to its value, the greater the suggesting that tailings dam horizontal deformation is mainly located near the dam slope, and gradually decreases from left to right in the law, therefore, dry beach face of deformation is smaller than the deformation of dam slope. 


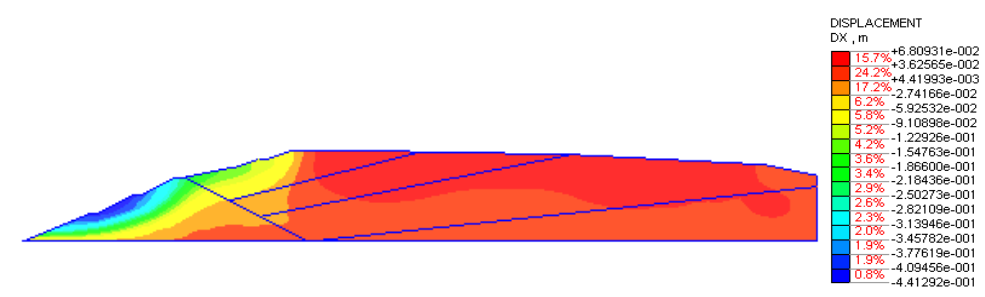

Figure 3.1.2 Currently the dam (750m elevation) horizontal displacement contour plot

Figure3.1.3 is $750 \mathrm{~m}$ elevation 3.1.3 dam deformation stability after horizontal principal stress contour map. Overall, the shape of the contour is similar to the shape of the dam. And can be seen from the diagram, the farther away from the beach face slope and dry place, the greater value of the horizontal direction of the principal stress, which appears near the dam site of the maximum principal stress in the dam bottom. Comparing the two figures can be found that the same location, the condition of maximum principal stress than normal water level conditions ${ }^{[8]}$, these are mainly related to the gravity.

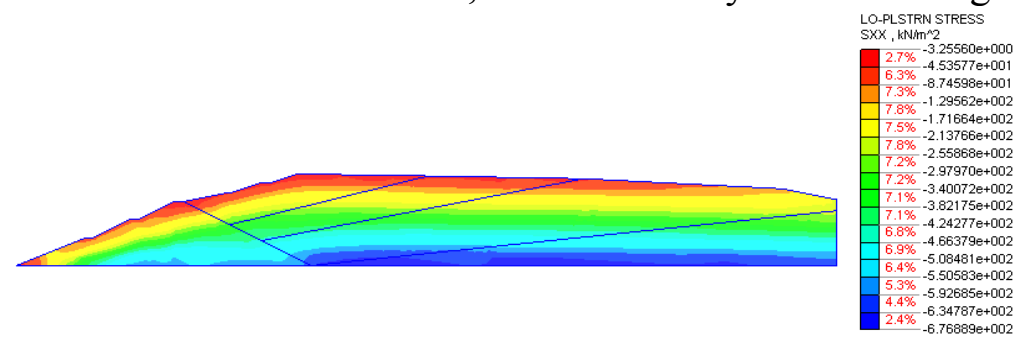

Figure 3.1.3 Currently the dam (750m elevation) horizontal principal stress contour map

Figure 3.1.4 for dam deformation stability at the natural water condition of shear stress contour map, the map shows that stress, high in the dam body, mainly in the initial dam and fill dam on the left side of the position near the dam slope, dam near the dam foundation in the early years of the maximum shear stress, which appear on the other areas are relatively small, are distributed in shear stress contour curve of approximate circular arc shape ${ }^{[9]}$, and the position of maximum shear stress is the arc center.

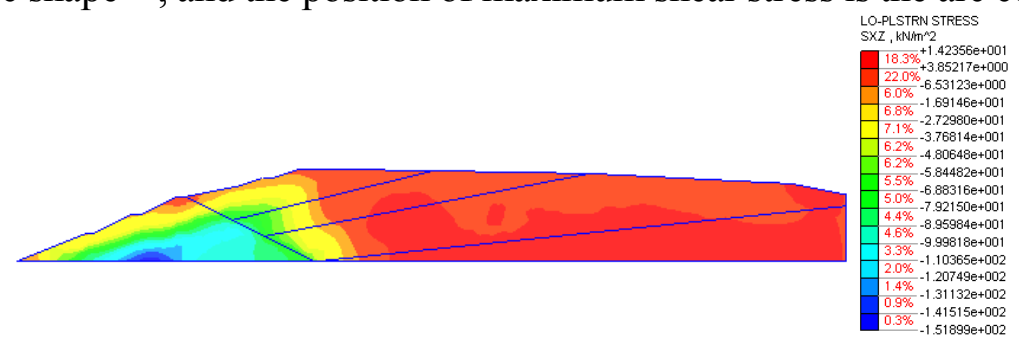

Figure 3.1.4 Currently the dam (750m elevation) shear stress contour map

Figure 3.1.5 for the elevation of the dam in the natural water condition of the distribution of shear strain nephogram, can be concluded that the initial dam site are the large shear strain, and large shear strain area, shows that it is the most easy to damage, with the rise of water level, the dam shear strain increases. This is because the water level rises in tailings dam dry beach length decreases, and saturation line position, water gradually into the pore of tailings, and has certain lubrication effect, the solid skeleton of the whole dam body up support ${ }^{[10]}$, which reduces the shear strength of tailings dam.

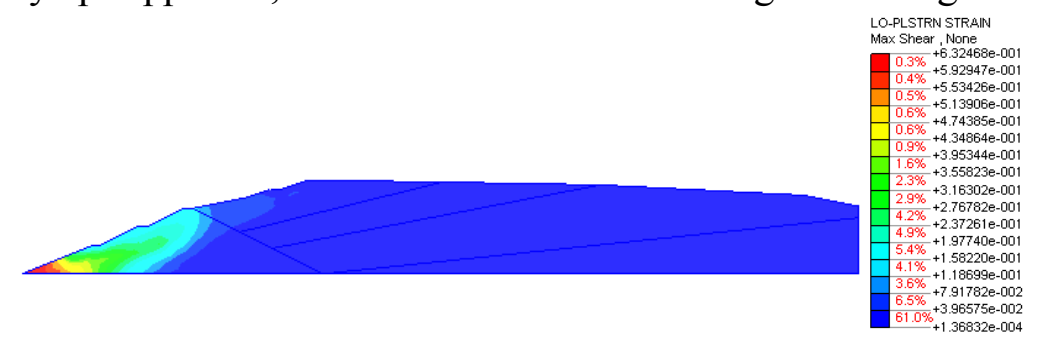

Figure 3.1.4 Currently the dam (750m elevation) maximum shear strain 
(2) Heightened to elevation of $775 \mathrm{~m}$

When finally heightening to $775 \mathrm{~m}$ elevation, calculate and analyze the model. The safety coefficient under the condition of normal water level were 1.46, the same specific analysis process with 3.1, without detailed list. Now carry on the summary of leaking point elevation and corresponding seepage stability coefficient on the situation of now and the heightenning dam body under various conditions, as shown in table 3.2.1.

Table 3.2.1 Summary of seepage stability calculation results

\begin{tabular}{|cccccc|}
\hline elevation & working condition & $\begin{array}{c}\text { leaking point } \\
\text { elevation } / \mathrm{m}\end{array}$ & Surface method & $\begin{array}{c}\text { Assumed sliding } \\
\text { CSF }\end{array}$ & 3D numerical simulation \\
\hline \multirow{2}{*}{$750 \mathrm{~m}$} & normal water & 707.5 & 1.65 & 2.53 & 1.51 \\
& flood level & 711.3 & 1.52 & 1.94 & 1.39 \\
& normal water & 715.0 & 1.43 & 1.72 & 1.36 \\
& flood level & 720.0 & 1.30 & 1.51 & 1.25 \\
\hline
\end{tabular}

Sort the above-mentioned data,and map it into 3.2.1. As you can see, using the same material parameters, different calculation method leads to identical minimum safety coefficient, three different curve from left to right all showed a trend of gradual decline, and the curve is almost linear relationship, showing that the higher leakage point of saturation line, the smaller the corresponding minimum safety coefficient of dam body, which is reflected in engineering is that a higher position of seepage line leads to an more unstable dam body.

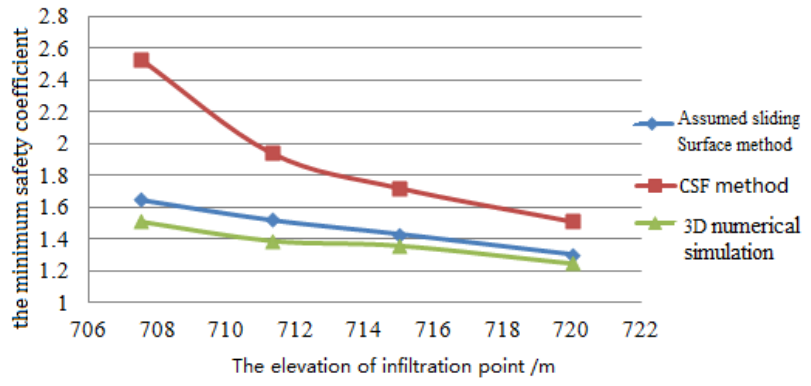

Fig 3.2.1 Infiltration point elevation and stability coefficient under different calculation method

\section{Summary}

In different working conditions, considering the seepage effect and the function of gravity stress, applying the limit equilibrium theory and critical sliding field technology of slope ,under different shape of saturation line ,the stability of arch dam is calculated, then use MIDAS software to a calculation of three dimensional numerical simulation of dam body under the design and the level elevation, drawing the following conclusion:

(1) By calculating the stability of dam under working condition of normal water level and the flood level , the minimum safety coefficient can satisfy the requirements of specification, showing a stable state on both natural water and flood conditions.

(2) Piled up to level $775 \mathrm{~m}$ eventually, the stability coefficient calculated of dam body meet the specification requirement under flood level, but security surplus is not big enough, so in the later ,there should be a reasonable planning and design in the process ,and take effective measures for draining leakage, to avoid an accident in the rainy season .

(3) Analyze different distribution characteristics of seepage line effect on the stability of tailings dam, the results show that it leads to a higher penetration point of the water level of the rolls, the decrease of corresponding coefficient of dam body stability, thus verify the conclusion that the rise of phreatic line can reduce stability

(4) Critical sliding field technology overcomes the improper assumption that the characteristics of the sliding surface often is not consistent with the engineering practice, using it to search the sliding 
surface, and combined with the limit equilibrium method to calculate the stability coefficient which is more scientific, so it has a wide application prospect in the tailings stability evaluation.

\section{Acknowledgements:}

This research has been funded by The National Natural Science Foundation of China (No.41172250),National five-year science and technology support project (2012BAK09B06),The innovative team project of Beijing (IDHT20140501), The scientific research base construction, scientific research innovation platform, scientific research and special - impact pressure build of microseismic monitoring and early warning system (XN083) and New type of anchor reinforcement technique field test research and graduate student ability training (XN107).

\section{References}

[1] Mascaro. Mine wastes at the polymetallic deposit of Fenice Capanne (southern Tuscany, Italy). Mineralogy, geochemistry, and environmental impact [J]. Environmental Geology , 2001, 41(4): 417 429.

[2] Ghose MK, Sen PK. Investigation of soil engineering properties for safe design and construction of the iron ore tailing dam[J]. Indian Journal of Engineering and Materials Sciences,2001, 8 (6): $318 \sim 326$.

[3] Ahsene Bouhrouxn.Xinghui Liu and Fanlk Civan.Predictive Model and Verification for Sand Particulates Migration in Gravel Packs. SPE28534.

[4] Sammarco O. A Tragic Disaster Caused by the Failure of Tailings Dams Leads to the Formation of the Stava 1985 Foundation[J]. Mine Water and the Environment, 2004, 23(2): 91 95.

[5] Garga VK, de la Torre M. Emergency remediation of instability at Caudalosa tailings dam, Peru:a case history[J]. Canadian Geotechnical Journal, 2002, 39 (5): 1193 1200.

[7] Herman Bouwer, Jamie Ludke,Robert C.Rice.Sealing pond bottoms with muddy water[J].Ecological Engineering,2001,18:233 238.

[8] Rykaart M, Fredlund M, Stianson J. Modelling tailings dam flux boundary conditions with 3D seepage software[J]. Ground Engineering, 2002, 35(7): 28 30.

[9] Skolasińska K. Clogging microstructures in the vadose zone-laboratory and field studies[J].Hydrogeology Journal, 2006, 14(6): 1005 1017.

[10] K.Mohd.Azizli, Kyoung Woong Kim. Characteristics of tailings from the closed metal mines as potential contamination source in South Korea[J]. Environmental Geology, 2001, 41 (3), 358 364. 